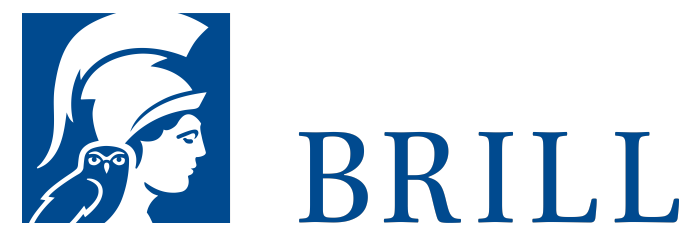

\title{
Eine Maschine, die wirkt
}

Die Elektrokrampftherapie und ihr Apparat, 1938-1950

Author: Max Gawlich

Die Elektroschocktherapie gilt als eine Ikone der technisierten Medizin des 2o. Jahrhunderts und ihres Zugriffs auf den Menschen. Doch fehlte bislang historische Forschung zu ihrer Technik. Diese Studie untersucht umfassend und international vergleichend die Gestaltung der EKT in den 1940er Jahren. Max Gawlich betrachtet mittels Fallstudien aus Deutschland, Großbritannien und der Schweiz die technische Entwicklung und klinische Einführung der Elektrokrampftherapie. Er stützt sich dabei auf umfangreiches technisches und klinisches Archivmaterial und durchleuchtet kritisch die therapeutische Erprobung und Entwicklung im Wechselspiel von Ingenieuren, Ärzten, Patienten und Pflegern.

Zudem untersucht er die medialen, praktischen und epistemischen Strategien im Umgang mit den unbekannten Apparaten im Klinikalltag. Darüber hinaus identifiziert er die Aufschreibetechniken und Apparate der Therapie sowie die therapeutische Praxis und analysiert sie hinsichtlich der Konzepte Wirksamkeit, Nichtwissen und Lokalität der Anwendung.

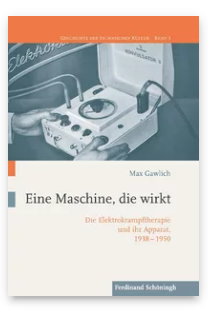

Pages: 378

Seiten, $47 \mathrm{~s} / \mathrm{w}$

Abb.

Language:

German

Subjects:

Cultural History,

Literature and

Cultural Studies

Publisher: Brill |

Schöningh

Series:

Geschichte der

technischen

Kultur, Volume:

3

E-Book (PDF)

Released online:

24 Nov 2017

ISBN: 978-3-

657-78736-4

List price

Hardback

Publication date:

10 Nov 2017

ISBN: $978-3^{-}$

506-78736-1

List price 
Biographical Note

Max Gawlich studierte Geschichte, Historische Hilfswissenschaften und Jüdische Studien.

For more information see brill.com

\begin{abstract}
Order information: Order online at brill.com +44330 333 0049 | customerservices@brill.com Submission information: brill.com/authors
\end{abstract}

Titles published by Brill | Fink, Brill | mentis or Brill | Schöningh: +49(o)71 5413279216 | brill@brocom.de 